\title{
Feline trichogranuloma: A Case Report
}

\section{Julia Guimarães ${ }^{1}$, Aline Silvestrini da Silva², Fernanda Campos Hertel ${ }^{2}$, Stefany Dias Teixeira ${ }^{2}$, Dayana Alersa Conceição Ferreira-Ermita², Laydianne Graciette Abreu de Oliveira Souza $^{2}$, Clairton Marcolongo Peireira ${ }^{*}$, Jéssica Miranda Cota ${ }^{1}$}

\author{
${ }^{1}$ Faculty of Veterinary Medicine, Centro Universitário do Espirito Santo - UNESC, Colatina, Brazil, ${ }^{2}$ Faculty of \\ Veterinary Medicine, Universidade Federal de Viçosa - UFV, Viçosa, Brazil.
}

\begin{abstract}
Trichogranuloma is characterized by a foreign body-type granulomatous inflammatory process resulting from the presence of hair fragments in the dermis. We report a case of a two-year-old male cat, presenting pain and an increase in volume in the right pelvic limb. Physical examination revealed a nodular lesion that drained a purulent secretion. The diagnosis of trichogranuloma was made based on clinical findings and histological changes. Trichogranulomas are rare in animals and humans; they are usually an occupational disease of hairdressers. Therefore, this condition must enter into the differential diagnosis of other granulomatous diseases in cats, such as infection by Mycobacterium spp. and Nocardia spp., among others.
\end{abstract}

Keywords | Granuloma, Dermatopathology, Inflammation, Fistula, Feline

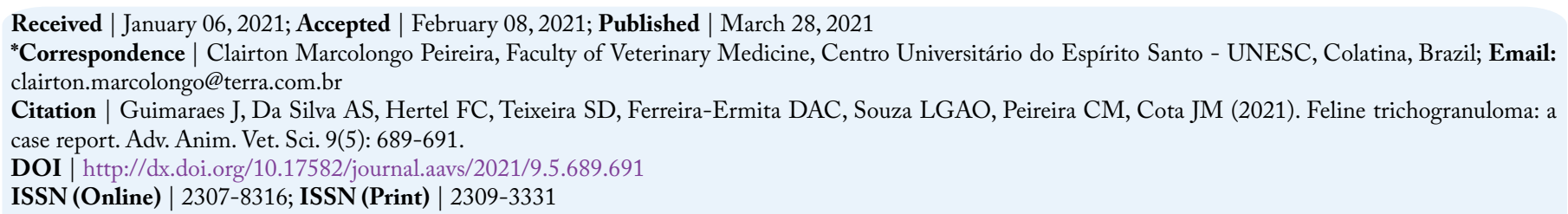

Copyright (C) 2021 Peireira et al. This is an open access article distributed under the Creative Commons Attribution License, which permits unrestricted use, distribution, and reproduction in any medium, provided the original work is properly cited.

\section{INTRODUCTION}

$\mathrm{T}$ richogranuloma is a rare disease in cats, which develops when hair fragments penetrate the skin and promote a foreign body-type granulomatous dermal reaction (Lopes et al., 2018; Siddiqui, 2020). In humans, trichogranulomas usually appear as inflamed nodules, which can be painful and/or pruritic, and are associated with occupational disease in hairdressers (Rochenbach et al., 2006, Lopes et al., 2018). They occur when fragments of hair penetrate the skin during the exercise of the profession and start an inflammatory reaction with the late formation of a cyst or a polyp (Siddiqui et al., 2020). In histology, follicles can be replaced by a nodular accumulation of neutrophils or eosinophils, macrophages and plasma cells, located in the center of the inflammatory focus, with some plasma cells on the periphery, being then called granulomas, which contain giant cells that they can be organized around frag- ments of free hair and form tricogranulomas or around free keratin, forming keratogranulomas (Gonzalez, 2008; Cheville, 2009).

Although trichogranuloma has been recognized in veterinary medicine to affect dogs (Gross et al., 2005), appearing like as papules, nodules and / or plaques. Its occurrence in cats is unusual (Prisco et al., 2008), and no other reports have been known in the dermatological literature ever since. Thus, the objective of this study was to report a case of trichogranuloma in a cat emphasizing the clinical characteristics and histopathological findings.

\section{CASE REPORT}

\section{CASE HISTORY AND CLINICAL FINDINGS}

A mixed-breed, 2-year-old male cat presented with an 
enlargement of the lateral region of the right pelvic limb, accompanied by itching and pain. The enlargement grew over the course of two months. During the physical examination, an increase in nodular volume was observed in the limb (Figure 1A), which drained a purulent secretion. Tramadol hydrochloride $(1 \mathrm{mg} / \mathrm{kg})$ and amoxicillin with clavulanate $(22 \mathrm{mg} / \mathrm{kg})$ were prescribed for 10 days, and complete resolution of the condition was observed. After 45 days, lesion recurrence was observed.
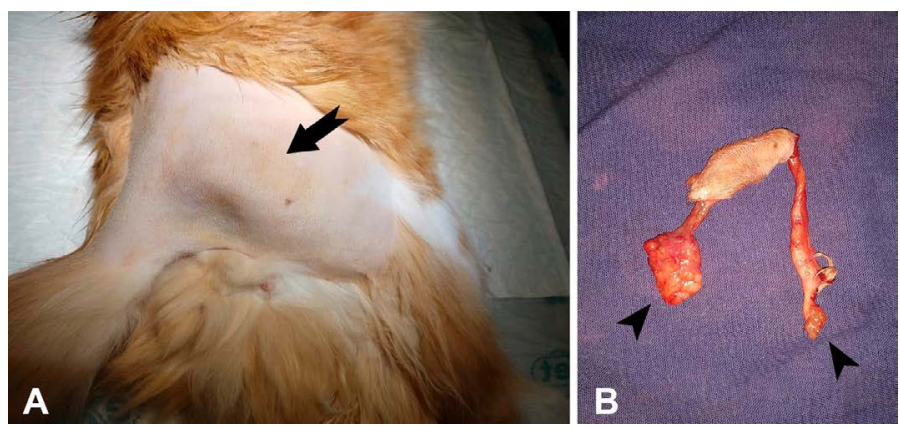

Figure 1:Trichogranuloma in a cat. A. Right pelvic limb showing a firm elastic nodular mass (arrow). B. Surgical excision of the nodular mass showing two tubelike structures (fistulous tract) with blind edges (arrow heads).

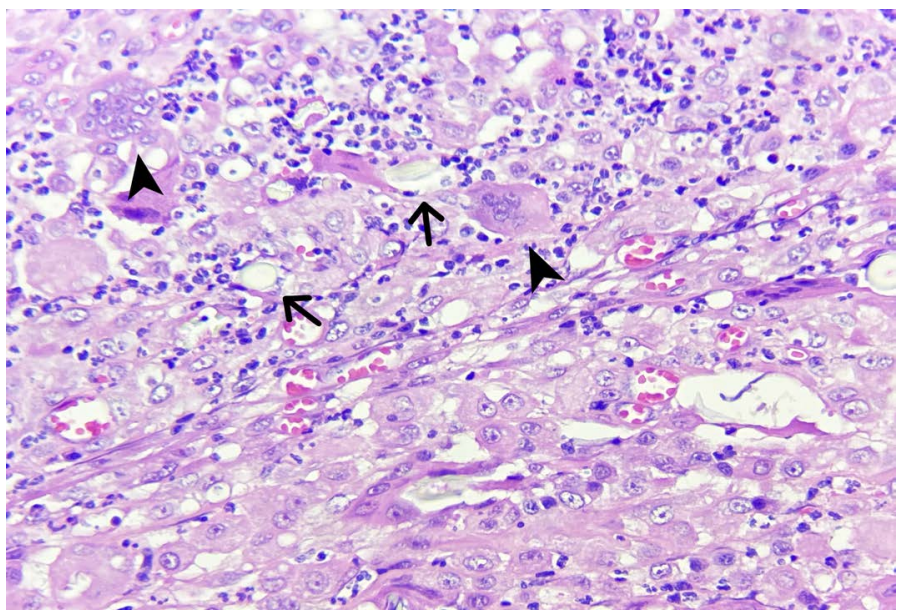

Figure 2: Trichogranuloma in a cat. Cutaneous nodule. There are fragments of free hair shaft (arrows) surrounded by giant foreign body cells (arrow heads) and leukocytic infiltration. (400 X, H\&E).

\section{SurgicAl PROCEDURE AND Biopsy}

Considering the clinical aspect of the lesion and recurrence, a biopsy was recommended for histopathological analysis. During the surgical procedure, it was observed that inside the mass, there were two fistulous paths that did not communicate with each other and ended in blind bottoms (Figure 1B) interspersed in the gluteal muscles. A sample of the tissue were collected for histopathological evaluation. The fragment was fixed in $10 \%$ buffered formalin solution, processed routinely for histology and stained with Hematoxylin and Eosin (H\&E) and Fite-Faraco (modified acid-fast stain). It was not possible to perform microbiological analysis of the sample.

\section{HistopathologicAl Findings}

Macroscopically, they were observed inside the removed nodule. Microscopically, fragments of the free hair shaft were observed, surrounded by giant foreign body cells and a mixed inflammatory infiltrate composed of neutrophils, lymphocytes, and plasma cells (Figure 2). Sometimes giant cells are seen to have phagocyte fragments. Special Fite-Faraco (modified acid-fast stain) staining was performed to identify acid-resistant alcohol bacteria, in which the presence of bacteria was not observed.

\section{DISCUSSION}

The diagnosis of trichogranuloma in a cat was based on histological findings characterized by the presence of a foreign body-type granulomatous inflammatory process and the presence of fragments of intralesional hair. Granulomatous changes comprise a wide variety of lesions that have the formation of granulomas as a common histological characteristic (James, 1999). Granulomas are characterized by a focal and compact collection of inflammatory cells, mainly lymphocytes and macrophages, and are formed by the presence and persistence of non-degradable products and active hypersensitivity (James, 1999). Granulomas are usually associated with a response to infectious agents, autoimmune diseases, toxic agents, allergens, neoplasms, and foreign bodies (Shah et al., 2017). Most of the cases diagnosed as tricogranuloma were in short-haired dogs, which suggests the coat is a predisposing factor for the development of the lesion in dogs (Amarante, 2012). In this case, the triggering factor was the presence of free intradermal hair, which the organism recognizes as a foreign body and triggers a histiocytic reaction without an adaptive immune response.

Foreign body-type granulomas are more commonly seen in dogs than in cats, and there is no predilection for sex or age (Amarante, 2012). It is believed that the rarity of this type of injury in cats is because the species is more prone to careful self-grooming, avoiding the appearance of foreign body-types reactions (Prisco et al., 2008). However, in this case, self-grooming may have predisposed the cat to the injury. According to the study by Amarante (2012), the diagnoses of tricogranulomas corresponded to $13.8 \%$ of the autoimmune skin diseases studied in dogs and were not associated with the sex or age of the animals. In another study by Machado et al. (2018), epidermal inclusion cysts (39.74\%) and trichogranuloma (15.38\%) were the most frequently diagnosed in dogs with tumoral skin diseases. In humans, trichogranuloma is a rare occupational disease of hairdressers that develops when hair clippings penetrate the skin and cause a foreign-body reaction (Lopes et al., 
In this study, the formation of fistulous paths was observed in the material removed from the cat. In humans, the chronic inflammatory reaction has been associated with the formation of fistulas and cystic cavities filled with hair fragments and surrounded by granulation tissue (Scharl and Rogler, 2014).

Clinically, the cat had increased volume, local pain, and itching. Similar data are described in animals with foreign bodies, in which erythema and swelling can be observed, followed by the formation of the firm, fistulated nodules or abscesses draining seropurulent or serosanguineous exudates (Prisco et al., 2008).

In this study, Fit Faraco staining was performed to search for acid-resistant alcohol bacteria that may be associated with the formation of granulomatous lesions in animals. Several infectious agents, such as Mycobacterium ssp., Leishmania spp., Cryptococcus spp., Toxoplasma gondii, Nocardia spp., and others can cause granulomatous lesions (Morris \& Dobson, 2001) and should be included in the differential diagnosis of trichogranuloma in cats.

There are few studies in the veterinary literature on cats tricogranuloma, mainly on macroscopic findings and the clinical correlation with cutaneous trauma, as described in humans. For this reason, this work emphasizes the importance of including tricogranuloma as a differential diagnosis in chronic fistulas in cats.

\section{ACKNOWLEDGMENT}

This work was supported by Fundação de Amparo à Pesquisa e Inovação do Espírito Santo (FAPES), and was financed in part by the Coordenação de Aperfeiçoamento de Pessoal de Nível Superior (CAPES), Brasil-Finance code 001 .

\section{CONFLICT OF INTEREST STATEMENT}

The authors have declared no conflict of interest.

\section{AUTHORS ‘CONTRIBUTIONS}

All authors contributed equally to the design and writing of the manuscript. All authors critically reviewed the

\section{REFERENCES}

-Amarante CF (2012).Análise Epidemiológica das Dermatopatias de uma População Canina Atendida no Período de 2005 a 2010 no Setor de Dermatologia do Hospital Veterinário da Universidade Federal Rural do Rio de Janeiro. Thesis (Master's degree) - Universidade Federal Rural do Rio de Janeiro, Veterinary Science Graduate Course.114f.

- Cheville NF (2009). Introdução à patologia veterinária. 3d ed. Manole, Barueri, SP. 4: 115-116.

- González LJ (2008). Estudio histopatologico de dermatopatias no neoplasicas em el perro. Degree work - Universidade de La Salle, Faculty of Veterinary Medicine, Bogotá.

- Gross TL, Ihrke PJ, Walder EJ, Affolter VK (2005). Skin Diseases of the dog and cat, Clinical and histopathologic Diagnosis. 2nd ed. Blackwell Science Ltd. 27: 714-715. https://doi.org/10.1002/9780470752487

- James GD (1999). A clinicopathological classification of granulomatous disorders. Postgrand. Med. J. 76(898): 457465. https://doi.org/10.1136/pmj.76.898.457

-Lopes BC, Grant I. Adler AI (2018). Trichogranuloma in a Hairdresser with Systemic Sclerosis. Cureus. 10(5): e2690. https://dx.doi.org/10.7759\%2Fcureus.2690

- Machado Gessica AC, Fontes TN, Laranjeira DF, EstrelaLima A, Moreira Eduardo LT, Ribeiro LS, Pinto Marcela PR, Peixoto TC (2018). Incidence of skin tumors in dogs in Salvador, Bahia state, Brazil (2007-2016). Pesquisa Veterinária Brasileira. November 38 (11): 2139-2145. http:// dx.doi.org/10.1590/1678-5150-pvb-5686

-Morris J, Dobson J (2001). Small Animal Oncology. Blackwell Science Ltd. 4: 66-67. https://doi. org/10.1002/9780470690406

- Prisco M, Ciaramella P, Santoro D (2008). Cutaneous sterile granulomas/pyogranulomas, leishmaniasis and mycobacterial infections. J. Small Anim. Pract. 49: 552-561. https://doi. org/10.1111/j.1748-5827.2008.00638.x

- Rockenbach IA, Guim TN, Zanin AA, Vaz S, Fernandes CG (2006). Levantamento da casuística de cistos cutâneos em caninos e felinos no período de 2001 a 2006. In: Congresso de iniciação científica, 15, Pelotas.

- Scharl M, Rogler G (2014). Pathophysiology of fistula formation in Crohn's disease. World J. Gastroint. Pathophysiol. 5(3):205-212. https://doi.org/10.4291/wjgp.v5.i3.205

-Shah KK, Pritt BS, Alexander MP (2017). Histopathologic review of granulomatous inflammation. J. Clin. Tubercul. Mycobact. Dis. 7: 1-12. https://doi.org/10.1016/j. jctube.2017.02.001

- Siddiqui B, Faridi SH, Vasenwala SM, Ansari H (2015). Trichogranuloma of the external auditory canal mimicking aural polyp: A rare case report. Archv.ed.Health Sci. 320322. https://doi.org/10.4103/2321-4848.17194 